\title{
BMJ Open Evidence-based quality indicators for primary healthcare in association with the risk of hospitalisation: a population- based cohort study in Switzerland
}

\author{
Carola A Huber (D) , ${ }^{1,2}$ Martin Scherer, ${ }^{3}$ Roland Rapold, ${ }^{1}$ Eva Blozik, ${ }^{1,2}$ The Swiss \\ Quality Indicator for Primary Care (SQIPRICA) Working Group members were
}

To cite: Huber CA, Scherer M, Rapold R, et al. Evidence-based quality indicators for primary healthcare in association with the risk of hospitalisation: a population-based cohort study in Switzerland. BMJ Open 2020;10:e032700. doi:10.1136/ bmjopen-2019-032700

- Prepublication history and additional material for this paper are available online. To view these files, please visit the journal online (http://dx.doi. org/10.1136/bmjopen-2019032700).

Received 01 July 2019 Revised 20 February 2020 Accepted 26 March 2020

A Check for updates

C Author(s) (or their employer(s)) 2020. Re-use permitted under CC BY-NC. No commercial re-use. See rights and permissions. Published by BMJ.

${ }^{1}$ Department of Health Sciences, Helsana Insurance Group, Zürich, Switzerland

${ }^{2}$ Institute of Primary Care, University of Zürich, University Hospital Zürich, Zürich,

Switzerland

${ }^{3}$ Department of General

Practice/Primary Care, University Medical Center HamburgEppendorf, Hamburg, Germany

Correspondence to

Dr Carola A Huber;

carola.huber@helsana.ch

\section{ABSTRACT}

Objectives The quality of ambulatory care in Switzerland is widely unknown. Therefore, this study aimed to evaluate the recently proposed quality indicators (Qls) based on a nationwide healthcare claims database and determine their association with the risk of subsequent hospitalisation at patient-level.

Design Retrospective cohort study.

Setting Inpatient and outpatient claims data of a large health insurance in Switzerland covering all regions and population strata.

Participants 520693 patients continuously insured during 2015 and 2016.

Measures A total of 24 Qls were obtained by adapting the existing instruments to the Swiss national context and measuring at patient-level. The association between each $\mathrm{Ql}$ and hospitalisation in the subsequent year was assessed using multiple logistic regression models.

Results The proportion of patients with good adherence to Qls was high for the secondary prevention of diabetes and myocardial infarction (glycatedhaemoglobin ( $\mathrm{HbA1C}$ ) control, 89\%; aspirin use, 94\%) but relatively low for polypharmacy (53\%) or using potentially inappropriate medications (PIMs) in the elderly (PIM, 33\%). Diabetesrelated indicators such as the $\mathrm{HbA} 1 \mathrm{C}$ control were significantly associated with a lower risk of hospitalisation ( $0 \mathrm{R}, 0.87 ; 95 \% \mathrm{Cl}, 0.80$ to 0.95 ), whereas the occurrence of polypharmacy and PIM increased the risk of hospitalisation in the following year (OR, 1.57/1.08; $95 \%$ $\mathrm{Cl}, 1.51$ to $1.64 / 1.05$ to 1.12 ).

Conclusions This is the first study to evaluate the recently presented Qls in Switzerland using nationwide real-life data. Our study suggests that the quality of healthcare, as measured by these Qls, varied. The majority of Qls, in particular Qls reflecting chronic care and medication use, are considered beneficial markers of healthcare quality as they were associated with reduced risk of hospitalisation in the subsequent year. Results from this large practical test on real-life data show the feasibility of these Qls and are beneficial in selecting the appropriate Qls for healthcare implementation in general practice.

\section{INTRODUCTION}

Measuring and monitoring healthcare quality is a necessary precondition to draw
Strengths and limitations of this study

- This study assessed a large set of evidence-based quality indicators (QIs) for primary healthcare in the Swiss context.

- The predictive value of each QI on hospitalisation risk was also estimated.

- Findings were based on a nationwide health insurance claims database covering all parts of Switzerland.

- Claims data did not provide information about quality as reflected in patients' satisfaction, communication or decision-making.

healthcare providers' attention to the patients' need and to determine potential areas for improvement. It is the basis for the evaluation and implementation of targeted interventions to optimise the effectiveness and safety of healthcare. Since several quality measures in the literature are developed for measuring healthcare quality in the hospital setting or only at practice-level, defining quality standards for primary care at patientlevel is required. ${ }^{1-6}$ These standards ensure high-quality care in all countries and also facilitate the mutual learning process in global healthcare systems. National quality standards in primary care have been developed in several Western countries such as the UK, ${ }^{7}$ Germany, ${ }^{8-10}$ Australia $^{11}$ and the Netherlands. ${ }^{12}$ Considering the high healthcare expenditure $(12.3 \%$ of the gross domestic product) in Switzerland, the country with the second highest life expectancy rate among the Organisation for Economic Co-operation and Development member states, the Swiss healthcare system is often considered as one of the most highly performing healthcare systems worldwide. ${ }^{13}$ However, the quality of Swiss healthcare is widely unknown. Switzerland does not have a national framework for 
measuring healthcare quality in primary care, and instruments for measuring and reporting quality of ambulatory services across Switzerland are insufficient.

Therefore, in 2016, we launched the Swiss Quality Indicator for Primary Care (SQIPRICA) Project, which aimed to provide the first nationwide applicable and evidencebased set of indicators to measure the quality of primary care at patient-level in Switzerland. ${ }^{14}$ An independent multidisciplinary international expert group (the SQIPRICA group) rated the potential quality indicators (QIs) derived from international evidence sources, ${ }^{8-10}$ and these QIs were adapted by the Swiss health system. Based on a consensus process, which explicitly included the patient perspective, a set of 24 QIs was identified. The QIs covered a wide range of domains in the Swiss primary healthcare setting, including general and disease-specific aspects such as drug safety, care for elderly, physicians' efficiency and chronic disease management.

In this study, we measured the Swiss QIs in reallife settings and determined their association with an outcome at the patient-level. In contrast to evaluating the association between QIs and outcomes using aggregate data at the practice-level, analysis of individual patientlevel data allows for the harmonisation of definitions and better adjustment of systematic differences of patient characteristics across subgroups. ${ }^{15}$ Moreover, the development of valid measures of healthcare quality often requires a strong association between QIs and patientrelevant outcomes; however, most internationally existing studies on quality frameworks neglected it. ${ }^{16} 17$ One largely unique and good example is the experience from the pay-for-performance scheme, which has already been successfully implemented in the UK at the national level. ${ }^{18}$ Additionally, previous studies evaluating quality measures were conducted only in selected care situations such as the treatment of symptomatic gallstones or the prevention and management of cardiovascular diseases. ${ }^{13} 1920$

The present study aimed to evaluate the recently presented set of 24 QIs in primary care based on a nationwide, patient-level healthcare claims database in one of the largest health insurances in Switzerland and to determine the association between each QI and the risk of hospitalisation in the subsequent year at patient-level.

\section{METHODS}

\section{Study population and setting}

We conducted a retrospective cohort study using the data from one of the largest health insurance companies in Switzerland, the Helsana Insurance Group. This patientlevel database consists of anonymised pharmacy and medical and health services records of Helsana mandatory insured persons. Data can be considered representative for the general population, since $\sim 15 \%$ of the total population in Switzerland are included (covering all parts of the country). Every resident of Switzerland has the choice to be insured with Helsana health insurance. According to the Swiss Health Law, every resident of Switzerland must be insured with a compulsory health insurance. The health insurers are privately organised and every Swiss resident can choose every health insurer. The obligatory health insurance provided is defined at the federal level and is similar for all health insurance companies; therefore, a high degree of generalisability of the data can be assumed. The longitudinal information includes patients' sociodemographic characteristics, healthcare plan, prescribed drugs (substance, dose), laboratory tests, outpatient consultations and hospital discharges including diagnoses according to the International Classification of Diseases, $10^{\text {th }}$ revision (ICD10). The high quality of the Helsana database has been previously validated, and data were widely used to investigate the aspects of healthcare quality and several patient outcomes. ${ }^{21-24}$

Study subjects were considered eligible for inclusion in the study if they were aged $\geq 18$ years in 2015 and continuously covered by mandatory insurance at the Helsana Group between 1 January 2015 and 31 December 2016. Subjects living abroad, nursing home residents and patients with missing values (eg, incomplete cases) were excluded. The study included all healthcare invoices submitted to Helsana health insurance for reimbursement; however, deductibles (ranging from 300 to 2500 Swiss francs (CHF)) and cost sharing with $10 \%$ of the annual healthcare costs (up to $700 \mathrm{CHF}$ ) are obligatory for every Swiss resident. In exchange for reduced premiums, the standard deductible of $300 \mathrm{CHF}$ can be changed into a higher deductible of 500, 1500, 2000 or 2500 CHF. Nevertheless, the included invoices represent nearly all total medical expenses of the mandatory insured patients at Helsana since the majority of patients chose a low deductible (300 to $500 \mathrm{CHF}$ ), depending on the corresponding sample for each QI calculation from $70 \%$ (total sample) to $88 \%$ (sample of patients $\geq 65$ years and with $\geq 1$ medication prescription). However, most patients with a high chosen deductible still submitted their bills to Helsana and only $\sim 3 \%$ of the additional out-of-pocket payments were not send in (according to internal Helsana analysis). Since the proportion of unsubmitted invoices is very small in patients receiving medical services, the (cost) data were slightly underestimated.

The health insurance market is regulated by governmental departments, and every health insurance company is obligated to guarantee insurance to every resident. The catalogue of health services reimbursed by basic mandatory health insurance is the same across the country and across all health insurance models.

\section{Quality indicators}

\section{Development process}

We used a total of 24 previously defined Swiss QIs at the patient-level. The QI development process was based on a comprehensive screening of existing clinical guidelines recommended by the German Association of Primary Care and Family Medicine (DEGAM, 'Deutsche Gesellschaft für Allgemeinmedizin und Familienmedizin'), the German 
National Disease Management Guidelines (NVL, 'Nationale VersorgungsLeitlinien') and preexisting indicators from the QIs for Primary Care of the German Society of Quality Assurance (QISA, 'Qualitätsindikatorensystem für die ambulante Versorgung'). ${ }^{8-10}$ In the absence of national guidelines, the German standards for quality in primary care were considered suitable for application since several structural similarities exist between the Swiss and German healthcare system (social health insurance system including a mix of public and private healthcare providers, German-speaking area). According to internationally established research methods for developing QIs in primary care, a six-step development process was implemented. ${ }^{25}$ In a first step, all recommendations for or against specific medical interventions of all currently existing DEGAM and NVL guidelines and all QISA quality indicators were extracted. ${ }^{8-10}$ As a second step, this list of potentially eligible items for QI was checked for operationalisability on Swiss health insurance claims data. In a third step, a multidisciplinary group of nine independent experts (SQIPRICA Working Group) rated the list of potential QIs for relevance for public health, clarity of definition, influence on measured aspect of care, risk of undesired effects and strength of evidence. As a fourth step, in face-to face workshop consensus on a preliminary set of QIs was reached. The fifth step was a feasibility test (descriptive analysis) using claims data of 950000 adult persons with Swiss basic mandatory health insurance. As a sixth step, the final set of QIs was defined in an additional workshop. The final set of 24 indicators covered general and specific aspects of the quality in primary care. The general domains included two categories: (1) general quality aspects (QI.1, QI.2) and (2) efficiency of healthcare (QI.3 to QI.7). The specific aspects comprised the following three domains: (1) drug safety (QI.8, QI.9), (2) care for the elderly (QI.10 to QI.13) and (3) chronic disease management/the medication therapy of acute cardiovascular events (disease-specific, QI.14 to QI.24). Details of the development process are described elsewhere. $^{14}$

\section{Measurements}

The calculation of the single QIs was performed in 2015 and can be described as follows: QI.1 and QI.2 relate to the general aspects and were thus calculated in the total sample. For the calculation of QI.3 to QI.24, additional specific inclusion criteria were applied: QI.3, QI.8 and QI.9 relate to patient subgroups with $\geq 1$ prescription of each relevant medication class according to the WHO Anatomical Therapeutic Chemical (ATC) groups: ${ }^{26}$ proton pump inhibitors (PPIs), statins, angiotensin II (ATII) antagonists, ACE inhibitors, anxiolytics/sedatives/ hypnotics and non-steroidal anti-inflammatory drugs (NSAIDs). QI.3 calculates the drug costs of the given ATC group divided by the sum of the received defined daily dose (DDD) per person/year. Considering that the distribution of costs was heavily skewed and that cost figures could not easily be translated in good or poor quality of care, we cut the range of costs into four (QI.3) and six (QI.2) equally populated cost groups (with one exception: since the high costs in QI.2 were significantly prevalent, we divided it into two high-cost groups; the groups of QI.2 were not equally distributed). QI.4 and QI.5 relate to the efficiency of general medication prescriptions; thus, they were calculated in a subsample of persons with $\geq 1$ medication prescriptions irrespective of the drug class. QI.4 calculates the occurrence of prescribed generics versus the receipt of a prescribed original product with increased co-payment $(20 \%$ vs $10 \%) .{ }^{27}$ QI.5 reflects the existence of prescribed inefficient me-too medications including analogue drugs with no or only marginal differences to already launched drugs or drugs with unclear therapeutic value. The assignment was based on classifications developed by Fricke and Klaus. ${ }^{28}{ }^{29}$ QI.6 and QI.7 measure the number of different primary care physicians or specialists and were calculated in persons who had $\geq 1$ physician (primary care/specialist physician) consultation. The quality of care for the elderly is displayed in QI.10 to QI.13 and was thus assessed in the subsample of persons aged $\geq 65$ years. QI.10 and QI.11 reflect the drug safety in elderly patients with $\geq 1$ medication prescription: QI.10 measures 'polypharmacy' ( $>5$ different drug prescriptions in $\geq 1$ quarter per patient/year) and QI.11 'potentially inappropriate medications (PIM)' ( $\geq 1$ PIM prescription in $\geq 1$ quarter per patient/year). PIM was calculated based on ATC codes, the PRISCUS list (Latin for 'time-honoured'), and Beers criteria and included medications that had to be avoided in elderly patients due to evidence of increased complications and poor outcomes. ${ }^{30}{ }^{31}$ Another QI regarding care for the elderly was the influenza vaccination, which is displayed in QI.12. To determine the presence of hospitalisation for fractures near the pelvic joint (ICD-10 'S72.0x', QI.13), the presence of $\geq 1$ comorbidity (measured as pharmacybased cost group, PCG) was applied as an additional criterion. ${ }^{32}{ }^{33}$ QI.14 and QI.15 assessed the long-term therapy of systemic corticosteroids in two sequential quarters and the disease-specific hospitalisation (ICD-10 'J.44/45') in patients with respiratory diseases (presence of the corresponding PCG). QI.16 to QI.20 relate to patients with diabetes mellitus (measured as PCG 'diabetes') and evaluated the annual control of glycatedhaemoglobin (HbA1c), lipid and kidney values, the eyes and the occurrence of hospitalisation. The secondary prevention of myocardial infarction (ICD-10 'I.21') and stroke/transient ischaemic attack (TIA, ICD-10 'I.64', 'G.45') with the use of acetylsalicylic acid (aspirin, ASS) and statins in the 12 months following hospital discharge was reflected in QI.21 to QI.24. A detailed description of each indicator is provided in online supplementary table $\mathrm{S} 1$.

\section{Baseline covariates and outcome}

Several patient characteristics such as age, gender, region of residence (urbanisation, language), type of health insurance plan (deductibles 'low: 300 to 500 CHF' vs 'high: >500 CHF', supplementary/private insurance) and 
proxies for health status were obtained from the database in 2015. Patients' individual health status was approximated by the number of patients' chronic diseases and the incurred healthcare costs in the previous year (2014). According to the WHO ATC classification system, a total of 22 diseases were identified using the well-established pharmacy-based mapping approach for chronic conditions (PCGs). ${ }^{32}{ }^{33}$ Conditions comprised bone diseases (osteoporosis), cancer, cardiovascular diseases (including hypertension), dementia, diabetes mellitus, epilepsy, glaucoma, gout/hyperuricaemia, HIV infection, hyperacidityrelated disorders, hyperlipidaemia, iron deficiency anaemia, migraine, pain, Parkinson's disease, psychological disorders, psychoses, respiratory illness, rheumatological conditions, thyroid disorders and tuberculosis. In the absence of systematically recorded clinical diagnoses in the entire Swiss outpatient setting, this mapping approach provides a direct measure of the treated chronic conditions and is a commonly used and reliable method to identify chronically ill patients in administrative databases. ${ }^{345}$ The summarised measure 'number of chronic conditions' was categorised into four groups ( 0 to 1,2 to 3,4 to $5, \geq 6$ ). Healthcare costs incurred in the previous year were calculated and considered as surrogate for the medical history of the patients reflecting disease severity. They include all costs reimbursed by Swiss basic mandatory health insurance, excluding cost sharing of cantonal authorities and insured person (co-payments, deductibles). The outcome of interest was all-cause hospitalisation in 2016 (follow-up), defined as an overnight hospital stay within the year.

\section{Statistical analysis}

Sociodemographic variables and other baseline characteristics of the total study sample were summarised using descriptive statistics. Categorical variables were presented as percentages and continuous variables as means (SD). According to the definition of QIs, we computed the overall 16 subgroups to determine the percentage of patients meeting the corresponding QI. To validate the calculated QIs, for each QI, a multiple logistic regression model was performed to assess the independent association between QIs at baseline (2015) and all-cause hospitalisation at follow-up (2016); with exception of QIs that are already clearly utilisation measures (QI.1, QI.13, QI.15, QI.18). All performed regression models were controlled for the following patient characteristics: gender, age, region of residence, type of health insurance plan, proxies for health status (number of chronic conditions, healthcare costs in the previous year (2014)). The selection of the included independent variables was based on the current Swiss risk equalisation model. ${ }^{36}$ Besides age and gender, the regional variables were also included since the Swiss healthcare system is regulated at regional level (by canton); additionally, proxies for health status were defined as covariables because they strongly influence health outcomes. ${ }^{21}$ We included the summarised measure 'number of chronic conditions' (categories: 0 to
1,2 to 3,4 to $5, \geq 6$ ) as control variable because it reflects a simple index for chronic disease status. In literature, this kind of indexes is a very helpful and effective instrument to measure patients' health status and to reflect co-morbidity status. ${ }^{21}$ Using a comprehensive morbidity measure in every QI-analysis increased the comparability of our QI results.

Moreover, all regression models were separately performed for high-risk beneficiaries which were defined as follows: (1) Patients suffering from at least two chronic conditions simultaneously, and (2) Patients with at least two chronic conditions and high costs. The cut-off point of two conditions was used because studies have shown that the co-occurrence of two of more (chronic) conditions within one patient has a high impact on future adverse health outcomes such as hospitalisation. ${ }^{37} 38$ Patients with high costs were defined as the top $20 \%$ of patients incurring the highest healthcare costs in the previous year. ${ }^{39} 40$ We did not correct for multiple comparisons, since the selection of the QIs was theoretically based (derived from German national guidelines and adapted to the Swiss system by the SQIPRICA Working Group), and did not depend on the observed results. All 24 QIs were statistically tested and all results were reported. The QIs reflect different aspects of the healthcare quality and exist independently of each other. Statistical analyses were performed using the statistical programme R V.3.5.0 ( $\mathrm{R}$ Development Core Team 2018). Significance was determined at a level of 0.05 .

\section{Patient and public involvement}

Since we analysed already recorded health insurance claims data, patients or the public were not involved.

\section{RESULTS}

A total of 520693 patients were eligible for analysis in the baseline year (2015). Table 1 shows the patient characteristics of our study cohort. There were slightly more women (53\%) than men (47\%), and the mean age was 54 years. Regarding the geographical distribution, most persons lived in urban regions $(66 \%)$ and approximately a quarter of the population in the Latin-speaking areas of Switzerland. Almost $30 \%$ of the sample chose a deductible class greater than $500 \mathrm{CHF}$, and approximately a fifth chose a supplementary/private health insurance plan. The annual mean healthcare costs of basic mandatory health insurance per patient amounted to 4848 CHF in the previous year. Moreover, $41 \%$ of the study population had two or more chronic conditions as assessed using PCGs.

Table 2 presents the number of persons in the various subpopulations who required the calculation of the Swiss QIs. We defined the number of patients with respiratory disease and diabetes mellitus and revealed a prevalence of approximately $10 \%$ and $7 \%$, respectively. When the analytical sample was based on patients with a specific event (myocardial infarction, stroke or TIA), the number 
Table 1 Patient characteristics $(n=520$ 693)

\begin{tabular}{|c|c|}
\hline Variable & $\mathbf{N}(\%)$ \\
\hline \multicolumn{2}{|l|}{ Patient characteristics } \\
\hline \multicolumn{2}{|l|}{ Gender } \\
\hline Male & $244196(46.9)$ \\
\hline Female & $276497(53.1)$ \\
\hline Mean age $\pm S D$ & $53.5 \pm 19.1$ \\
\hline \multicolumn{2}{|l|}{ Age groups (in years) } \\
\hline '18-30’ & 73864 (14.2) \\
\hline ‘31-40’ & 72200 (13.9) \\
\hline '41-50' & 84720 (16.3) \\
\hline ‘51-60’ & $90412(17.4)$ \\
\hline '61-70’ & $85023(16.4)$ \\
\hline ‘71-80’ & $70074(13.5)$ \\
\hline ‘81-90’ & $38653(7.4)$ \\
\hline ' $\geq 91 '$ & $5747(1.1)$ \\
\hline \multicolumn{2}{|l|}{ Region of residence } \\
\hline \multicolumn{2}{|l|}{ Urban/rural region } \\
\hline Urban & $345733(66.4)$ \\
\hline $\begin{array}{l}\text { Intermediary (dense peri-urban area } \\
\text { and rural centres) }\end{array}$ & $105641(20.3)$ \\
\hline Rural & $69319(13.3)$ \\
\hline \multicolumn{2}{|l|}{ Language region } \\
\hline $\begin{array}{l}\text { German-speaking/French-speaking } \\
\text { area }\end{array}$ & $392953(75.5)$ \\
\hline Latin-speaking area & $127740(24.5)$ \\
\hline \multicolumn{2}{|l|}{ Health insurance plan } \\
\hline \multicolumn{2}{|l|}{ Deductible class } \\
\hline Low ( $\leq 500$ Swiss Francs) & $365383(70.2)$ \\
\hline High (>500 Swiss Francs) & $155310(29.8)$ \\
\hline \multicolumn{2}{|l|}{ Insurance coverage } \\
\hline Mandatory insurance (only) & $416098(79.9)$ \\
\hline $\begin{array}{l}\text { Mandatory and/or supplementary } \\
\text { insurance }\end{array}$ & $104595(20.1)$ \\
\hline \multicolumn{2}{|l|}{ Proxies for health status } \\
\hline \multicolumn{2}{|l|}{ Number of chronic conditions } \\
\hline $0-1$ & $308018(59.2)$ \\
\hline $2-3$ & $132454(25.4)$ \\
\hline $4-5$ & $57753(11.1)$ \\
\hline$\geq 6$ & 22468 (4.3) \\
\hline $\begin{array}{l}\text { Healthcare costs in the previous year } \\
(\text { mean } \pm S D) \text { in Swiss Francs }\end{array}$ & $4848 \pm 9833$ \\
\hline
\end{tabular}

of eligible patients was 1284 and 518, respectively. Online supplementary table S2 describes the outcome (hospitalisation) for each subsample used for the calculation of the QIs. Approximately $15 \%$ of the patients with at least one medication prescription in the baseline year (2015) were hospitalised in the following year (2016), whereas
Table 2 Patient inclusion criteria relevant for the calculation of the quality indicators ( $n=520693$ (total; corresponding to QI.1 and QI.2))

\begin{tabular}{|c|c|c|}
\hline Variable & $\begin{array}{l}\text { Corresponding } \\
\text { QI }\end{array}$ & $\mathbf{N}(\%)$ \\
\hline \multicolumn{3}{|l|}{$\begin{array}{l}\text { Inclusion criteria (for QI } \\
\text { calculation) }\end{array}$} \\
\hline \multicolumn{3}{|l|}{ Efficiency and drug safety } \\
\hline $\begin{array}{l}\geq 1 \text { primary care }(\mathrm{PC}) \\
\text { physician consultation }\end{array}$ & QI.6 & 368805 (70.8) \\
\hline $\begin{array}{l}\geq 1 \mathrm{PC} \text { or specialist } \\
\text { physician consultation }\end{array}$ & QI.7 & $441424(84.8)$ \\
\hline $\begin{array}{l}\geq 1 \text { prescription of any } \\
\text { medication }\end{array}$ & QI.4, QI.5 & $438116(84.1)$ \\
\hline $\begin{array}{l}\geq 1 \text { prescription of } \\
\text { proton pump inhibitors }\end{array}$ & QI.3 & $133475(25.6)$ \\
\hline $\begin{array}{l}\geq 1 \text { prescription of } \\
\text { statins }\end{array}$ & Q1.3 & 79217 (15.2) \\
\hline $\begin{array}{l}\geq 1 \text { prescription } \\
\text { of angiotensin II- } \\
\text { antagonists }\end{array}$ & QI.3 & $34945(6.7)$ \\
\hline $\begin{array}{l}\geq 1 \text { prescription of } A C E \\
\text { inhibitors }\end{array}$ & QI.3 & $33085(6.4)$ \\
\hline $\begin{array}{l}\geq 1 \text { prescription of } \\
\text { anxiolytics, sedatives } \\
\text { or hypnotics }\end{array}$ & QI.8 & 88233 (16.9) \\
\hline $\begin{array}{l}\geq 1 \text { prescription of } \\
\text { non-steroidal anti- } \\
\text { inflammatory drugs }\end{array}$ & QI.9 & $195721(37.6)$ \\
\hline \multicolumn{3}{|l|}{ Care for elderly } \\
\hline$\geq 65$ years old & QI.12 & $166053(31.9)$ \\
\hline $\begin{array}{l}\geq 65 \text { years old and } \geq 1 \\
\text { prescription of any } \\
\text { medication }\end{array}$ & QI.10, QI.11 & $146618(28.2)$ \\
\hline $\begin{array}{l}\geq 65 \text { years old and } \geq 1 \\
\text { chronic condition }\end{array}$ & QI.13 & $117529(22.6)$ \\
\hline \multicolumn{3}{|l|}{ Diseases } \\
\hline Respiratory disease & QI.14, QI.15 & $51246(9.8)$ \\
\hline Diabetes mellitus & QI.16-20 & $36715(7.1)$ \\
\hline Myocardial infarction & QI.21, QI.22 & $1284(0.2)$ \\
\hline $\begin{array}{l}\text { Stroke or transient } \\
\text { ischaemic attack }\end{array}$ & QI.23, QI.24 & $518(0.1)$ \\
\hline
\end{tabular}

QI, quality indicator.

the proportion of hospitalised patients receiving specific medications such as PPIs, statins and ATII antagonists was higher $(22 \%)$.

Table 3 depicts the 1-year prevalence of QIs measuring the general aspects and efficiency. QI.1 measures emergency hospital admission that contributes a rate of $4 \%$ in the total analytical sample. QI.2 divides the sample into six groups according to their annual medication costs (total): more than half of the sample incurred $420 \mathrm{CHF}$ or less in the year 2015. Regarding the efficiency of medication 


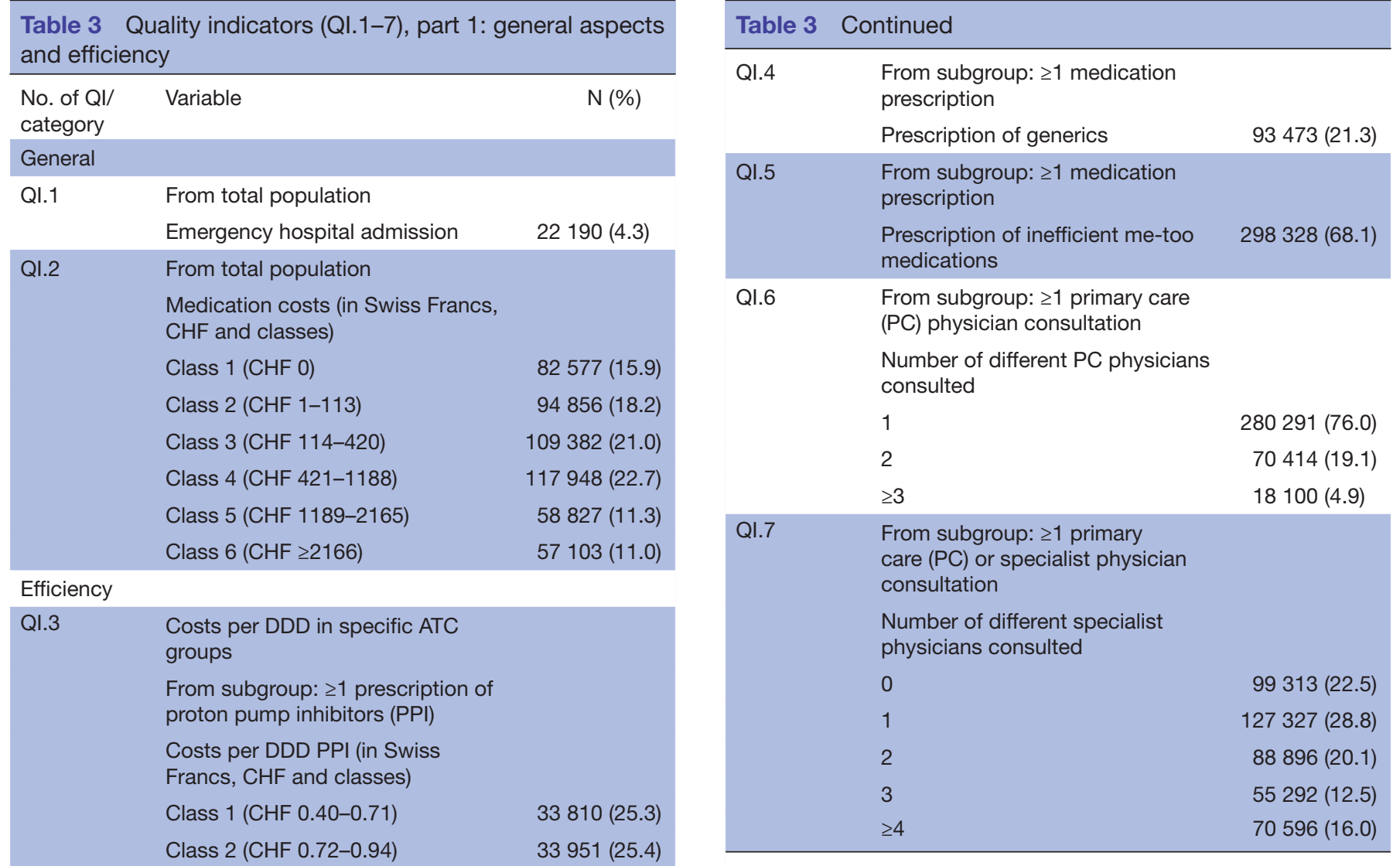

Class 3 (CHF 0.95-1.23)

Class 4 (CHF $\geq 1.24)$

$33799(25.3)$

31915 (23.9)

From subgroup: $\geq 1$ prescription of statins

Costs per DDD statins (in Swiss

Francs, CHF and classes)

Class 1 (CHF 0.18-0.54)

Class 2 (CHF 0.55-0.72)

Class 3 (CHF 0.73-1.18)

Class 4 (CHF $\geq 1.19)$

From subgroup: $\geq 1$ prescription of angiotensin II-antagonists (ATII)

Costs per DDD ATII (in Swiss Francs, CHF and classes)

Class 1 (CHF 0.16-0.36)

Class 2 (CHF 0.37-0.51)

Class 3 (CHF 0.52-0.69)

Class 4 ( $\mathrm{CHF} \geq 0.70$ )

From subgroup: $\geq 1$ prescription of ACE inhibitors

Costs per DDD ACE (in Swiss Francs, $\mathrm{CHF}$ and classes)

Class 1 (CHF 0.11-0.23)

Class 2 (CHF 0.24-0.31)

Class 3 (CHF 0.32-0.38)

Class 4 (CHF $\geq 0.39$ )
ATC, anatomical therapeutic chemical; DDD, defined daily dose; QI, quality indicator.

prescription, the costs per DDD of PPIs and statins were considerably higher than the costs of ATII antagonists and ACE inhibitors (QI.3). A generic medication was prescribed to approximately $20 \%$ of the patients (QI.4). Approximately $70 \%$ of the drug users were prescribed an inefficient me-too medication according to the classification of Fricke and Klaus (QI.5). QIs attributed to patients' consultation behaviour revealed that only $5 \%$ consulted three or more different primary care physicians (QI.6) and that, in contrast, $16 \%$ had consultations with at least four different specialist physicians (QI.7).

Table 4 displays the prevalence of QIs related to drug safety, care for the elderly and disease-specific QIs. QI.8 and QI.9 indicate the risk for overuse of anxiolytics/sedatives/hypnotics and NSAIDs, respectively. Approximately a quarter of each medication user group received three or more packages. QIs covering the aspects of care for the elderly (QI.10 to QI.13) revealed a relatively high proportion of persons aged $\geq 65$ years who received polypharmacy (QI.10, 53\%) and PIM (QI.11, 33\%), whereas a modest percentage of elderly patients received an influenza vaccination (QI.12, 18\%) or a hospitalisation for fracture near the pelvic point (QI.13, 0.3\%). Regarding chronic disease management, a considerable number of patients with diabetes mellitus received guideline-based healthcare (QI.16, HbA1c: 89\%; QI.17, ophthalmological control: 50\%; QI.19, control of lipid values: 64\%), and 
Table 4 Quality indicators (QI.8-24), part 2: specific aspects (drug safety, care for elderly and diseases-related)

$\begin{aligned} & \text { No. of QI/ Variable } \\ & \text { category }\end{aligned}$
N (\%)

Drug safety

QI.8 From subgroup: $\geq 1$ prescription of anxiolytics, sedatives or hypnotics

Number of prescriptions

49728

(56.4)

2

15490

(17.6)

$\geq 3$

23015

(26.1)

QI.9

From subgroup: $\geq 1$ prescription

of non-steroidal anti-inflammatory drugs

Number of prescriptions

1

108320

(55.3)

2

44700

(22.8)

$\geq 3$

42701

(21.8)

Care for elderly

\begin{tabular}{|c|c|}
\hline QI.10 & $\begin{array}{l}\text { From subgroup: } \geq 65 \text { years and } \geq 1 \\
\text { medication prescription }\end{array}$ \\
\hline & Polymedication \\
\hline
\end{tabular}

QI.11 From subgroup: $\geq 65$ years and $\geq 1$ medication prescription

Potentially inappropriate

48600 medication

QI.12

From subgroup: $\geq 65$ years

Influenza vaccination

30208

(18.2)

QI.13 From subgroup: $\geq 65$ years and $\geq 1$ chronic condition

Hospitalised for fracture near the $399(0.3)$ pelvic joint

\begin{tabular}{|c|c|c|}
\hline \multicolumn{3}{|c|}{ Disease-specific } \\
\hline \multirow[t]{2}{*}{ QI.14 } & $\begin{array}{l}\text { From subgroup: patients with } \\
\text { respiratory disease }\end{array}$ & \\
\hline & $\begin{array}{l}\text { Long-term therapy of } \\
\text { corticosteroids }\end{array}$ & $1106(2.2)$ \\
\hline \multirow[t]{2}{*}{ QI.15 } & $\begin{array}{l}\text { From subgroup: patients with } \\
\text { respiratory disease }\end{array}$ & \\
\hline & Disease-specific hospitalisation & $709(1.4)$ \\
\hline \multirow[t]{2}{*}{ Ql.16 } & $\begin{array}{l}\text { From subgroup: patients with } \\
\text { diabetes mellitus }\end{array}$ & \\
\hline & $\mathrm{HbA} 1 \mathrm{c}$ control & $\begin{array}{l}32770 \\
(89.3)\end{array}$ \\
\hline
\end{tabular}

Continued

\begin{tabular}{|c|c|c|}
\hline \multirow[t]{2}{*}{ Q.17 } & \multicolumn{2}{|l|}{$\begin{array}{l}\text { From subgroup: patients with } \\
\text { diabetes mellitus }\end{array}$} \\
\hline & Ophthalmological control & $\begin{array}{l}18493 \\
(50.4)\end{array}$ \\
\hline \multirow[t]{2}{*}{ Q.18 } & $\begin{array}{l}\text { From subgroup: patients with } \\
\text { diabetes mellitus }\end{array}$ & \\
\hline & Hospitalisation & 7303 (19.9) \\
\hline \multirow[t]{2}{*}{ QI.19 } & $\begin{array}{l}\text { From subgroup: patients with } \\
\text { diabetes mellitus }\end{array}$ & \\
\hline & Control of lipid values & $\begin{array}{l}23535 \\
(64.1)\end{array}$ \\
\hline \multirow[t]{2}{*}{ QI.20 } & $\begin{array}{l}\text { From subgroup: patients with } \\
\text { diabetes mellitus }\end{array}$ & \\
\hline & Control of kidney values & $\begin{array}{l}17345 \\
(47.2)\end{array}$ \\
\hline \multirow[t]{2}{*}{ QI.21 } & $\begin{array}{l}\text { From subgroup: patients with } \\
\text { myocardial infarction }\end{array}$ & \\
\hline & $\begin{array}{l}\text { Receiving ASS within } 12 \text { months } \\
\text { after event }\end{array}$ & $1210(94.2)$ \\
\hline \multirow[t]{2}{*}{ QI.22 } & $\begin{array}{l}\text { From subgroup: patients with } \\
\text { myocardial infarction }\end{array}$ & \\
\hline & $\begin{array}{l}\text { Receiving statins within } 12 \text { months } \\
\text { after event }\end{array}$ & $1127(87.8)$ \\
\hline \multirow[t]{2}{*}{ QI.23 } & $\begin{array}{l}\text { From subgroup: patients with } \\
\text { stroke or TIA }\end{array}$ & \\
\hline & $\begin{array}{l}\text { Receiving ASS within } 12 \text { months } \\
\text { after event }\end{array}$ & $391(75.5)$ \\
\hline \multirow[t]{2}{*}{ QI.24 } & $\begin{array}{l}\text { From subgroup: patients with } \\
\text { stroke or TIA }\end{array}$ & \\
\hline & $\begin{array}{l}\text { Receiving statins within } 12 \text { months } \\
\text { after event }\end{array}$ & $386(74.5)$ \\
\hline
\end{tabular}

ASS, aspirin; HbA1c, glycated haemoglobin; QI, quality indicator; TIA, transient ischaemic attack.

only a small number of patients with respiratory diseases underwent a long-term therapy of corticosteroids (QI.14, $2 \%)$ or were hospitalised due to disease-specific complications (QI.15, 1\%). ASS and statins were administered in the majority of patients after an acute myocardial infarction (QI.21 and QI.22, 90\%) and in three-quarters of the patients with stroke or TIA (QI.23 and QI.24, 75\%).

Figure 1 displays the multivariate regression results estimating the association between the QIs measuring general and efficiency aspects and patients' all-cause hospitalisation risk in the following year. After adjusting for sociodemographic characteristics and proxies for health status, all QIs except for QI.3 (categories of costs per DDD of relevant drug classes) indicated validity since their presence in a patient was associated with statistically significant increased risk of hospitalisation in the following year. Analysis of QI.2 showed a significant positive association: the higher the medication costs, the higher the risk of hospitalisation in the following year. Costs per DDD in 
Quality indicators (QI.2-7)

\begin{tabular}{|c|c|}
\hline \multicolumn{2}{|c|}{ General } \\
\hline \multirow{6}{*}{ QI.2 } & Medication costs (in classes) \\
\hline & Class 2 \\
\hline & Class 3 \\
\hline & Class 4 \\
\hline & Class 5 \\
\hline & Class 6 \\
\hline \multicolumn{2}{|c|}{ Efficency } \\
\hline \multirow[t]{17}{*}{ QI.3 } & Costs per DDD in specific ATC groups (in classes \\
\hline & Costs per DDD PPI \\
\hline & Class 1 \\
\hline & Class 2 \\
\hline & Class 3 \\
\hline & Costs per DDD statins \\
\hline & Class 1 \\
\hline & Class 2 \\
\hline & Class 3 \\
\hline & Costs per DDD ATII \\
\hline & Class 1 \\
\hline & Class 2 \\
\hline & Class 3 \\
\hline & Costs per DDD ACE \\
\hline & Class 1 \\
\hline & Class 2 \\
\hline & Class 3 \\
\hline QI.4 & Prescription of generics \\
\hline QI.5 & Prescription of inefficient me-too medications \\
\hline QI.6 & $\begin{array}{l}\text { No. of different primary care physicians consulted } \\
2 \\
\geq 3\end{array}$ \\
\hline \multirow[t]{5}{*}{ QI.7 } & No. of different specialist physicians consulted \\
\hline & 1 \\
\hline & 2 \\
\hline & 3 \\
\hline & $\geq 4$ \\
\hline
\end{tabular}

Odds ratio $(95 \% \mathrm{Cl})$

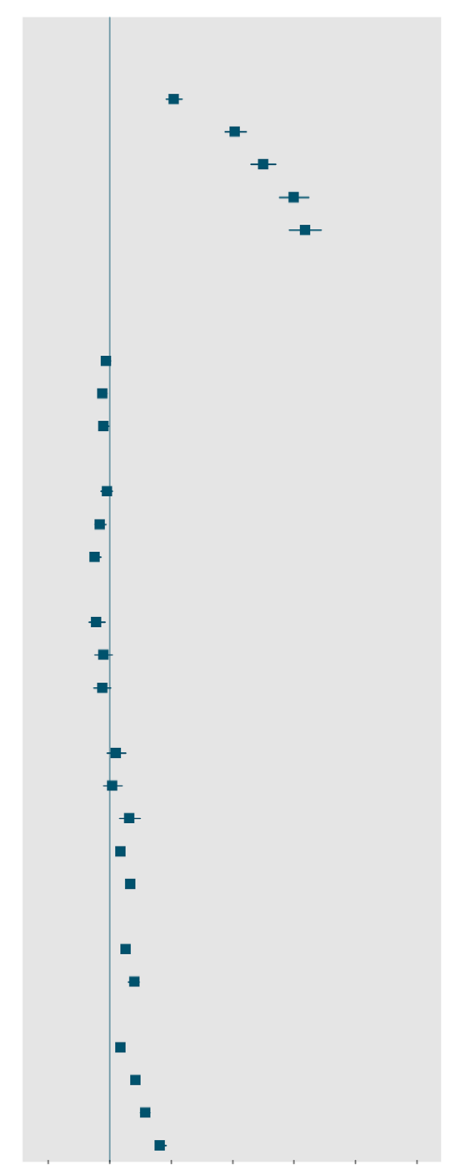

Odds ratio $(95 \% \mathrm{Cl})$

1.52 (1.46 to 1.59$)$

2.02 (1.94 to 2.11 )

2.25 (2.15 to 2.35 )

2.50 (2.38 to 2.62 )

2.59 (2.46 to 2.72 )

0.97 (0.94 to 1.01$)$

0.94 (0.91 to 0.98 )

0.95 (0.91 to 0.99$)$

$0.98(0.93$ to 1.02$)$

0.92 (0.88 to 0.97$)$

0.88 (0.84 to 0.93$)$

0.89 (0.83 to 0.96$)$

0.95 (0.88 to 1.02$)$

0.94 (0.87 to 1.01$)$

1.05 (0.98 to 1.13$)$

$1.02(0.95$ to 1.10$)$

1.16 (1.08 to 1.25$)$

1.09 (1.07 to 1.12$)$

$1.17(1.14$ to 1.20$)$

1.13 (1.11 to 1.16$)$

$1.20(1.15$ to 1.24$)$

$1.09(1.06$ to 1.12$)$

1.21 (1.18 to 1.24$)$

$1.29(1.25$ to 1.33$)$

$1.41(1.37$ to 1.46$)$

$\begin{array}{lllllll}0.5 & 1 & 1.5 & 2 & 2.5 & 3 & 3.5\end{array}$

selected ATC drug classes were not relevantly associated with hospitalisation risk (QI.3). Prescription of generics (QI.4) and prescription of me-too medications according to the classification of Fricke and Klaus (QI.5) indicated a slight increase in hospitalisation risk (OR, 1.09/1.17; $95 \%$ CI, 1.07 to $1.12 / 1.14$ to 1.20$)$. Additionally, the more primary care physicians consulted (QI.6), the higher the risk of hospitalisation in the following year, which was similar for the number of specialist physicians consulted (QI.7).

Figure 2 displays the estimates for QIs relating to specific aspects of care. The number of prescriptions of anxiolytics, sedatives or hypnotics (QI.8) was not associated with hospitalisation in the following year. In contrast, the more prescriptions of NSAIDs a patient received at baseline (QI.9), the higher was his or her probability of hospitalisation in the following year (OR, 1.05/1.12; $95 \%$ CI, 1.02 to $1.09 / 1.08$ to 1.15$)$. Moreover, the indicators displaying the quality of care for the elderly, such as receiving polypharmacy (QI.10) or PIM (QI.11), were statistically significantly associated with the odds of hospitalisation (OR, 1.57/1.08; 95\% CI, 1.51 to $1.64 / 1.05$ to $1.12)$. Patients who had received an influenza vaccination (QI.12) were more likely to be hospitalised than were patients who did not receive an influenza vaccination. Long-term therapy of systemic corticosteroids (QI.14) in patients with respiratory disease was strongly associated with hospitalisation in the following year (OR, 1.56; 95\% CI, 1.37 to 1.77 ). Chronically ill patients had lower rates of hospitalisations when they received the measures of secondary prevention. In patients with diabetes, HbA1c control (QI.16) and control of lipid values at baseline (QI.19) were statistically significantly associated with a decreased risk of hospitalisation in the following year (OR, $0.87 / 0.82 ; 95 \% \mathrm{CI}, 0.80$ to $0.95 / 0.77$ to 0.86 ). Ophthalmological control (QI.17) was not associated with hospitalisation risk. In contrast, control of kidney values (QI.20) was associated with a slight increase of the odds of hospitalisation. With respect to the secondary prevention of stroke or TIA, patients after stroke or TIA who received statins (QI.24) were less likely to be hospitalised in the following year than were non-users of statins (OR,0.59; 95\% CI, 0.36 to 0.97 ).

Online supplementary tables S3,S4 show the results of regressions for high-risk beneficiaries defined as patients with $\geq 2$ chronic conditions and patients with high costs and $\geq 2$ chronic conditions. Overall, the regression results were quite similar to the results based on the total sample, 


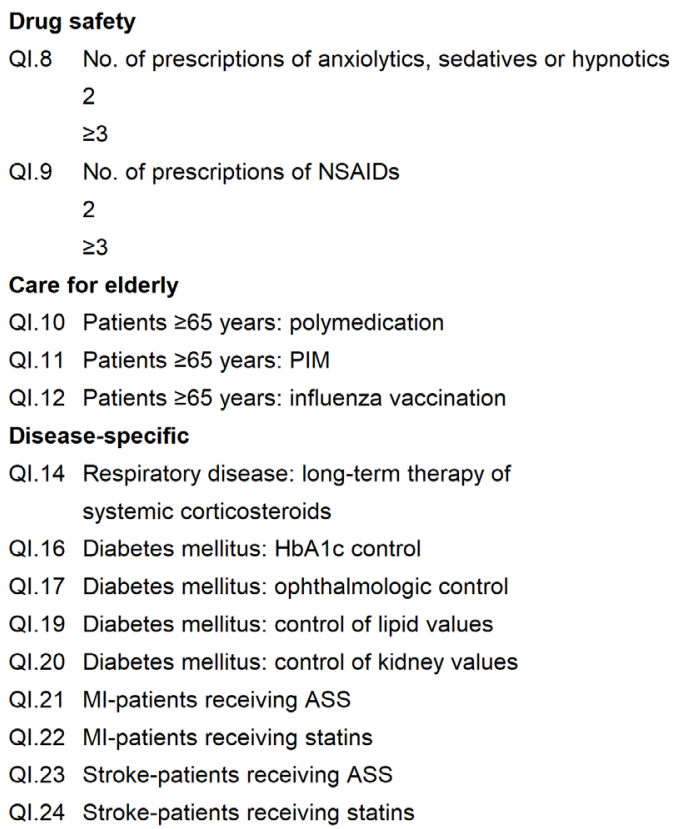



$\begin{array}{lllllll}0.5 & 1 & 15 & 2 & 25 & 3 & 35\end{array}$ but with some larger and some smaller ORs in these highrisk groups. Especially, QIs reflecting drug safety in elderly patients were stronger associated with the hospitalisation risk in both high-risk groups: the OR of polypharmacy (QI.10) and PIM (QI.11) were larger than in the high-risk groups compared with the total sample (polypharmacy: OR, 1.57; $95 \%$ CI, 1.51 to 1.64 (total) vs OR, 1.71/1.94; 95\% CI, 1.65 to $1.77 / 1.82$ to 2.07 (high-risk); PIM: OR, 1.08; $95 \%$ CI, 1.05 to 1.12 (total) vs OR, $1.15 / 1.17 ; 95 \%$ CI, 1.11 to $1.19 / 1.11$ to 1.23 (high-risk)). Additionally, in contrast to the total sample the high-risk group analysis showed a significant association between $\geq 3$ prescriptions of anxiolytics, sedatives or hypnotics (QI.8) and the hospitalisation risk in the following year (OR, 0.96; $95 \%$ CI, 0.92 to 1.00 (total) vs OR, $1.07 / 1.06 ; 95 \% \mathrm{CI}, 1.02$ to $1.11 / 1.01$ to 1.12 (high risk)). Furthermore, ORs of the number of different primary care physicians consulted (QI.6) were larger in the high-risk groups than in the total sample (OR, 1.20; $95 \%$ CI, 1.15 to 1.24 (total) vs OR, $1.25 / 1.23$; $95 \%$ CI, 1.19 to $1.30 / 1.16$ to 1.31 (high-risk)). On the other side, a few ORs were smaller or even not significant in the high-risk group analysis. For example, compared with the regression results of the total sample indicators reflecting medication costs such as QI.2 and QI.3 showed no significant association with the future hospitalisation risk in the high-risk group analysis (eg, QI.2 (class 6): OR, 2.59, 95\% CI; 2.46 to 2.72 (total) vs OR, $0.82 / 0.001 ; 95 \%$ CI, 0.07 to $9.34 / 0.92$ to 1.11$)$ ).

\section{DISCUSSION}

To the best of our knowledge, this is the first study that evaluated a large set of evidence-based QIs at a national level and determined the association between QI results and patient-relevant outcome measures. This is an important step toward proving data on healthcare quality and quantifying and comparing different quality aspects. The study revealed a clinically relevant and, in most cases, statistically significant association between the presence of QIs at patient-level and the risk of hospitalisation.

The previously presented set of 24 QIs that were based on evidence from the German guidelines and adapted to the Swiss healthcare system, resulting in the establishment of the multidisciplinary SQIPRICA Working Group panels, includes process indicators (16), healthcare cost indicators (4) and outcome indicators (4). In general, a broad spectrum of QIs indicated a close association with patient outcome. In particular, the indicators relating to chronic illness care, care for the elderly, medication use and relatively simple measures of coordination (number of healthcare physicians) are considered beneficial predictors of a beneficial outcome. Diabetes process and outcome indicators such as the annual control of HbA1c were significantly associated with a lower risk of hospitalisation in the following year. This finding is strongly consistent with the results of previous investigations showing a clear decrease in hospital admissions by improvements in quality of diabetic management. ${ }^{41}{ }^{42}$ Moreover, the compliance to indicators reflecting the quality of care in 
patients with respiratory diseases showed a positive association with outcomes, which is consistent with the result of previous studies. ${ }^{434}$

Furthermore, the present study emphasises the relevance of adverse drug reactions in the context of healthcare quality. Consistent with previous studies, polypharmacy and PIM were highly prevalent in patients aged 65 years or older, leading to an increased risk of hospitalisation and indicating intolerances and drug interactions among the elderly. ${ }^{22} 4546$ Moreover, analyses of the high-risk groups showed a stronger association between polypharmacy or PIM and the hospitalisation risk in the following year compared with the total sample. This finding indicates the very high risk of adverse drug reactions in vulnerable patient groups and stresses that the awareness of drug safety should be urgently increased especially in high-risk patients suffering from multimorbidity and/or patients with high healthcare costs as indicator for a high burden of disease ${ }^{47} 48$ Additionally, estimates referring to the different physician consultations revealed a relatively simple, but potent, predictor of outcome, which is consistent with the results of previous studies, indicating a better coordination in terms of the benefit of continuity of care together with improved quality of care. ${ }^{49}{ }^{50}$ Interestingly, compared with ASS use, the use of statins after stroke or TIA was found to be highly protective (QI.24). Generally, for QIs relating to clinical events, the number of cases tends to be significantly small in a small country such as Switzerland for the comparison of practices, physician networks or regions (QI.21-24).

Additionally, the influenza vaccination was not positively associated with the outcome, which can be explained as follows: First of all, there is only a small proportion of patients who received an influenza vaccination (18\%), which may reflect the inconsistent practice resulting from unclear medical recommendations in Switzerland. Moreover, we assume that the patients with influenza vaccination had a higher risk of hospitalisation since they reflect the sample with a high burden of disease. The results are likely to depict a selection of highly morbid patients. This explanation is in line with current study results from Switzerland which showed that influenza vaccination was significantly associated with a low self-reported health status and the occurrence of several chronic diseases such as diabetes mellitus and lung diseases (bronchial asthma, chronic bronchitis and emphysema). ${ }^{51}$

Prescription of generics (QI.4) and prescription of me-too medications (QI.5) indicated a slight increase in hospitalisation risk. We assume that these two measures are not useful in the Swiss healthcare system. The operationalisation of these QIs is not suitable since the two indicators are not markers for generics but rather for patient characteristics. Both were imported from Germany, where the market and the incentives for generics are different, and the definition of me-too drugs is also market-specific. Further research is needed to refine indicators reflecting inefficient medication prescriptions. In contrast, costs per DDDs do not seem to be negatively associated with quality, which is considered a positive finding when increasing the cost-efficiency of medication prescription.

\section{Strengths and limitations}

The present study has several strengths. First, it responds to the current public debates on quality assurance in ambulatory care. Second, this study evaluated the given Swiss adapted quality indicators for the first time in the Swiss healthcare setting and provides new insights for the stakeholder. Furthermore, the study findings might therefore contribute to encourage researchers to also evaluate their indicators and to publish the results. This might also help to increase acceptance of indicators and to increase transparency related to the development and evaluation of these measures. Third, the study was based on a large real-life data set of a broad spectrum of patients from all parts of Switzerland. Claims are available nationwide and underlie a standardised format and relatively high level of data control mechanisms. Fourth, the present project was based on a triangular approach consisting of (1) evidence from highly reliable sources, (2) adaptation to the local context and inclusion of the patient perspective and (3) data-based evaluation. However, several limitations also need to be considered. First, our study population was not entirely representative of the general Swiss population and had minor differences regarding sex, age groups and the region of residence, but the Helsana population covers insurers from all parts of Switzerland and includes all age groups and patient subgroups. ${ }^{52}{ }^{53} \mathrm{~A}$ recently published Helsana study could show that the Helsana population is only slightly older (mean percentage difference (mean diff.) of all age groups: $0.04 \%$ ), had a slightly higher percentage of women (diff.: $0.4 \%$ ) and very slightly varied regarding overrepresentation/underrepresentation of persons in only a few cantons (eg, canton Geneva; mean diff. of all cantons: $0.64 \%) .{ }^{52}$ Second, considering the nature of claims data information about quality as reflected in patients' satisfaction, communication and decision-making were not addressed. Third, clinical diagnoses from the outpatient setting were not available for adjustment in multivariate models. However, we used the well-established PCGs as proxies for ambulatory diagnoses to adjust for the differences in the risk of hospitalisation. Fourth, our results displayed the quality of healthcare from the mandatory health insurance perspective and did not include data from supplementary private insurance data. However, the basic mandatory insurance catalogue in Switzerland covers all services used for the present analysis. Finally, although we carefully adjusted for all variables that might interfere with hospitalisation risk available in our database, it is not possible to verify the causal association due to the cohort study design.

\section{Implications for future studies}

Several future research issues can be derived from our findings: Contrary to clinical events or relatively rare situations, future studies should predominately focus on highly prevalent chronic conditions (additional QIs). 
For the first attempts of implementation, it seems to be reasonable to focus on QIs reflecting chronic care and drug safety. Future QIs that focus on coordination and continuity of care would be also highly relevant. Moreover, the set of QIs might be supplemented by QIs derived from other sources such as the smarter medicine initiative. Additionally, the aspect of intersectoral problems, care coordination and interdisciplinary collaboration is not yet explicitly targeted in the current set of QIs. However, the issue is of increasing importance and a matter of ongoing political discussion. ${ }^{54}$ Additionally, the present study indicates that QIs focussing on specific clinical events such as myocardial infarction or stroke are limited by relatively small numbers of cases, which is even more relevant when small units such as care regions or specific patient strata should be monitored. Future studies are required to identify additional QIs targeting highly prevalent chronic conditions or clinical situations. Moreover, most of the indicators in the current set focussed on processes. Future studies are required to identify additional QIs measuring the quality of outcomes. Additionally, certain QIs such as influenza vaccination should be improved, supplemented or refined. Finally, future studies should evaluate if and how QIs derived from health insurance claims are supplemented with QIs derived from other sources (patient surveys, official statistics).

\section{CONCLUSIONS}

This is the first practice test of a previously proposed set of QIs that are principally available across Switzerland as they are based on the standardised format of Swiss health insurance claims data. The study revealed that constructing these indicators is feasible. Quality as measured by these QIs varies. The majority of QIs, in particular QIs reflecting chronic care and medication use, are considered beneficial markers of quality of care as they were associated with reduced risk of hospitalisation in the subsequent year. Furthermore, the study indicates that some QIs, such as influenza vaccination, require reevaluation and further refinement. In conclusion, the study is beneficial in identifying the starting points for initiatives to improve the quality of primary care in Switzerland. It provides further evidence when utilising the health insurance claims data available across all regions, healthcare settings and patient populations for assessing, monitoring and exchanging data on the quality of primary care.

Acknowledgements We thank the Wiley Editing Service for professional proofreading of the manuscript.

Collaborators The Swiss Quality Indicator for Primary Care (SQIPRICA) Working Group members were: Dr med Felix Huber, Medical Director, MediX Group Practices Zürich, Zürich, Switzerland; Rahel Meier, MSc, Research Associate, Institute of Primary Care, University of Zürich, Switzerland; Dr med Jan von Overbeck, Cantonal Physician, Canton of Bern, Bern, Switzerland; Dr Oliver Reich, Head of Santé24, Swica Insurance, Winterthur, Switzerland; Professor Dr med Thomas Rosemann, Director, Institute of Primary Care, University of Zürich, Switzerland; Felix Schneuwly, Head of Public Affairs Swiss Online Comparative Service Comparis, Zürich, Switzerland; Professor Dr Martin Scherer, Director Department of General Practice/PrimaryCare, Hamburg University Medical School, Hamburg-Eppendorf,
Hamburg, Germany; Professor Dr med Oliver Senn, Institute of Primary Care, University of Zürich, Zürich, Switzerland; Med Pract Daniel Tapernoux, Medical Advisor, Swiss Patient Organisation (SP0), Zürich, Switzerland.

Contributors All authors were involved in the study design. CAH, EB and MS conceived and designed the study. RR analysed the data. CAH drafted the manuscript. EB, RR, MS and the members of the Quality Indicator for Primary Care Working Group revised the manuscript. All authors participated in the interpretation of data, critically reviewed for important intellectual contents and gave the final approval of the version to be published.

Funding The authors have not declared a specific grant for this research from any funding agency in the public, commercial or not-for-profit sectors.

Competing interests None declared.

Patient consent for publication Not required.

Ethics approval According to the national ethical and legal regulation (the Swiss Federal Law of data protection), an ethical approval and patient consent were not required. Analyses were based on anonymised data.

Provenance and peer review Not commissioned; externally peer reviewed.

Data availability statement Data are available upon reasonable request. The data sets analysed in the study are not publicly available because they are part of the confidential Helsana health insurance claims database. Additional information not included in the paper is available from the corresponding author on reasonable request.

Open access This is an open access article distributed in accordance with the Creative Commons Attribution Non Commercial (CC BY-NC 4.0) license, which permits others to distribute, remix, adapt, build upon this work non-commercially, and license their derivative works on different terms, provided the original work is properly cited, appropriate credit is given, any changes made indicated, and the use is non-commercial. See: http://creativecommons.org/licenses/by-nc/4.0/.

ORCID iD

Carola A Huber http://orcid.org/0000-0002-2469-0435

\section{REFERENCES}

1 Beck SL, Dunton N, Berry PH, et al. Dissemination and implementation of patient-centered indicators of pain care quality and outcomes. Med Care 2019;57:159-66.

2 Shortell SM, Bennett CL, Byck GR. Assessing the impact of continuous quality improvement on clinical practice: what it will take to accelerate progress. Milbank Q 1998;76:593-624.

3 van den Bosch CMA, Geerlings SE, Natsch S, et al. Quality indicators to measure appropriate antibiotic use in hospitalized adults. Clin Infect Dis 2015;60:281-91.

4 Huang C, Loewen P, Pelletier T, et al. Implementation of proven interventions in general medical inpatients: development and evaluation of a new quality indicator for drug therapy. Qual Saf Health Care 2008;17:269-74.

5 Price D, Howard M, Dolovich L, et al. Practice-Based collection of quality indicator data for a comprehensive quality assessment programme in Canadian family practices. Qual Saf Health Care 2010;19:e47.

6 Engels Y, Dautzenberg M, Campbell S, et al. Testing a European set of indicators for the evaluation of the management of primary care practices. Fam Pract 2006;23:137-47.

7 Kontopantelis E, Reeves D, Valderas JM, et al. Recorded quality of primary care for patients with diabetes in England before and after the introduction of a financial incentive scheme: a longitudinal observational study. BMJ Qual Saf 2013;22:53-64.

8 Programme for National Supply Guidelines of BÄK, KBV and AWMF [Programm für Nationale VersorgungsLeitlinien von BÄK, KBV und AWMF]. Quality Indicators - Manual for Authors [Qualitätsindikatoren - Manual for Autoren], 2009. Available: https://www.aezq.de/mdb/ edocs/pdf/schriftenreihe/schriftenreihe36.pdf [Accessed $23 \mathrm{Apr}$ 2019].

9 AQUA-Institute. General methods in the context of crosssectoral quality assurance in health care [Allgemeine Methoden im Rahmen der sektorenübergreifenden Qualitätssicherung im Gesundheitswesen]. Available: https://www.aqua-institut.de/ fileadmin/aqua_de/Projekte/248_Methodenpapier/Methodenpapier_ 4.0.pdf [Accessed 23 Apr 2019].

10 German College of General Practitioners and Family Physicians [Deutsche Gesellschaft für Allgemeinmedizin und Familienmedizin]. 
S3 Guidelines of DEGAM - the Ten Step Plan [S3-Leitlinien der DEGAM - der Zehnstufenplan]. Available: https://www.degam. de/files/Inhalte/Leitlinien-Inhalte/Dokumente/Fuer\%20LeitlinienEntwickler/10-Stufen-Plan_Langfassung_20131112.pdf [Accessed 23 Apr 2019].

11 The Royal Australian College of General Practitioners. Standards for general practices. 5th edn. South Melbourne, Australia: RACGP, 2017.

12 Grol R. Quality development in health care in the Netherlands, 2006.

13 OECD. Health at a glance: Europe. OECD, 2018.

14 Blozik E, Reich O, Rapold R, et al. Evidence-Based indicators for the measurement of quality of primary care using health insurance claims data in Switzerland: results of a pragmatic consensus process. BMC Health Serv Res 2018;18:743.

15 Schuetz P, Wirz Y, Sager R, et al. Effect of procalcitonin-guided antibiotic treatment on mortality in acute respiratory infections: a patient level meta-analysis. Lancet Infect Dis 2018;18:95-107.

16 Marshall M, Klazinga N, Leatherman S, et al. OECD health care quality indicator project. The expert panel on primary care prevention and health promotion. Int J Qual Health Care 2006;18 Suppl 1:21-5.

17 Engels Y, Campbell S, Dautzenberg M, et al. Developing a framework of, and quality indicators for, general practice management in Europe. Fam Pract 2005;22:215-22.

18 Mendelson A, Kondo K, Damberg C, et al. The effects of pay-forperformance programs on health, health care use, and processes of care: a systematic review. Ann Intern Med 2017;166:341-53.

19 Campbell SM, Ludt S, Van Lieshout J, et al. Quality indicators for the prevention and management of cardiovascular disease in primary care in nine European countries. Eur J Cardiovasc Prev Rehabil 2008;15:509-15.

20 Harboe KM, Anthonsen K, Bardram L. Validation of data and indicators in the Danish cholecystectomy database. Int J Qual Health Care 2009;21:160-8.

21 Huber CA, Schneeweiss S, Signorell A, et al. Improved prediction of medical expenditures and health care utilization using an updated chronic disease score and claims data. J Clin Epidemiol 2013:66:1118-27.

22 Blozik E, Rapold R, von Overbeck J, et al. Polypharmacy and potentially inappropriate medication in the adult, community-dwelling population in Switzerland. Drugs Aging 2013;30:561-8.

23 Bähler C, Signorell A, Blozik E, et al. Intensity of treatment in Swiss cancer patients at the end-of-life. Cancer Manag Res 2018;10:481-91.

24 Huber CA, Meyer MR, Steffel J, et al. Post-Myocardial infarction (MI) care: medication adherence for secondary prevention after $\mathrm{Ml}$ in a large real-world population. Clin Ther 2019;41:107-17.

25 Campbell SM, Braspenning J, Hutchinson A, et al. Research methods used in developing and applying quality indicators in primary care. BMJ 2003;326:816-9.

26 WHO Collaborating Centre for Drug Statistics Methodology. Guidelines for ATC classification and DDD assignment 2019, 2018. Available: https://www.whocc.no/filearchive/publications/2019 guidelines web.pdf [Accessed 24 Apr 2019].

27 Swiss Federation. Ordinance of the federal department of home Affairs on benefits in compulsory health insurance, 2019. Available: https://www.admin.ch/opc/de/classified-compilation/19950275/ index.html\#a38a

28 Schwabe UPD. Arzneiverordnungs-Report 2016. Berlin: Springer, 2016.

29 Fricke UKW. New drugs 1986/87. Progress in drug therapy? [Neue Arzneimittel 1986/87. Fortschritte für die Arzneimitteltherapie? Stuttgart: Wissenschaftliche Verlagsgesellschaft mbH, 1987.

30 Holt S, Schmiedl S, Thürmann PA. Potentially inappropriate medications in the elderly: the PRISCUS list. Dtsch Arztebl Int 2010;107:543-51.

31 American Geriatrics Society 2012 Beers Criteria Update Expert Panel. American geriatrics Society updated beers criteria for potentially inappropriate medication use in older adults. J Am Geriatr Soc 2012:60:616-31.

32 Huber CA, Szucs TD, Rapold R, et al. Identifying patients with chronic conditions using pharmacy data in Switzerland: an updated mapping approach to the classification of medications. BMC Public Health 2013;13:1030.

33 Lamers LM, Vliet RCJA. Health-based risk adjustment improving the pharmacy-based cost group model to reduce gaming possibilities. Eur J Health Econ 2003;4:107-14.
34 O'Shea M, Teeling M, Bennett K. The prevalence and ingredient cost of chronic comorbidity in the Irish elderly population with medication treated type 2 diabetes: a retrospective cross-sectional study using a national pharmacy claims database. BMC Health Serv Res 2013;13:23.

35 Chini F, Pezzotti P, Orzella L, et al. Can we use the pharmacy data to estimate the prevalence of chronic conditions? A comparison of multiple data sources. BMC Public Health 2011;11:688.

36 Common Institution of Health Insurance Law. Risk adjustment [Risikoausgleich, Gemeinsame Einrichtung Krankenversicherungsgesetz], 2020.

37 Freund T, Kunz CU, Ose D, et al. Patterns of multimorbidity in primary care patients at high risk of future hospitalization. Popul Health Manag 2012;15:119-24.

38 Bähler C, Huber CA, Brüngger B, et al. Multimorbidity, health care utilization and costs in an elderly community-dwelling population: a claims data based observational study. BMC Health Serv Res 2015;15:23.

39 Meyers JL, Parasuraman S, Bell KF, et al. The high-cost, type 2 diabetes mellitus patient: an analysis of managed care administrative data. Arch Public Health 2014;72:6.

40 Rice JB, White A, Lopez A, et al. High-Cost sarcoidosis patients in the United States: patient characteristics and patterns of health care resource utilization. J Manag Care Spec Pharm 2017;23:1261-9.

41 Dusheiko M, Doran T, Gravelle H, et al. Does higher quality of diabetes management in family practice reduce unplanned hospital admissions? Health Serv Res 2011;46:27-46.

42 Huber CA, Brändle M, Rapold R, et al. A set of four simple performance measures reflecting adherence to guidelines predicts hospitalization: a claims-based cohort study of patients with diabetes. Patient Prefer Adherence 2016;10:223-31.

43 Leuppi JD, Schuetz P, Bingisser R, et al. Short-Term vs conventional glucocorticoid therapy in acute exacerbations of chronic obstructive pulmonary disease: the reduce randomized clinical trial. JAMA 2013;309:2223-31.

44 Walters JA, Gibson PG, Wood-Baker R, et al. Systemic corticosteroids for acute exacerbations of chronic obstructive pulmonary disease. Cochrane Database Syst Rev 2009:1:CD001288.

45 Albert SM, Colombi A, Hanlon J. Potentially inappropriate medications and risk of hospitalization in retirees: analysis of a US retiree health claims database. Drugs Aging 2010;27:407-15.

46 Endres HG, Kaufmann-Kolle P, Steeb V, et al. Association between potentially inappropriate medication (PIM) use and risk of hospitalization in older adults: an observational study based on routine data comparing PIM use with use of Pim alternatives. PLOS One 2016;11:e0146811.

47 Brockmöller J, Stingl JC, Multimorbidity SJ. Multimorbidity, polypharmacy and pharmacogenomics in old age. Pharmacogenomics 2017;18:515-7.

48 American Geriatrics Society Expert Panel on the Care of Older Adults with Multimorbidity. Guiding principles for the care of older adults with multimorbidity: an approach for clinicians. J Am Geriatr Soc 2012;60:E1-25.

49 O'Malley AS, Cunningham PJ. Patient experiences with coordination of care: the benefit of continuity and primary care physician as referral source. J Gen Intern Med 2009;24:170-7.

50 Peikes D, Chen A, Schore J, et al. Effects of care coordination on hospitalization, quality of care, and health care expenditures among Medicare beneficiaries: 15 randomized trials. JAMA 2009;301:603-18.

51 Zürcher K, Zwahlen M, Berlin C, et al. Trends in influenza vaccination uptake in Switzerland: Swiss health survey 2007 and 2012. Swiss Med Wkly 2019;149:w14705.

52 Haller E, Watzke B, Blozik E, et al. Antidepressant prescription practice and related factors in Switzerland: a cross-sectional analysis of health claims data. BMC Psychiatry 2019;19:196.

53 Huber CA, Schwenkglenks M, Rapold R, et al. Epidemiology and costs of diabetes mellitus in Switzerland: an analysis of health care claims data, 2006 and 2011. BMC Endocr Disord 2014:14:44.

54 Swiss Federal Office of Public Health. Fact sheet of the project "Coordinated Care", 2019. Available: https://www.bag.admin.ch/ $\mathrm{bag} / \mathrm{de} / \mathrm{home} / \mathrm{strategie}-\mathrm{und}$-politik/nationale-gesundheitspolitik/ koordinierte-versorgung.html 